\title{
Aspect and argument realization: A study on antecedentless null objects in Greek
}

\author{
Ianthi Maria Tsimpli*, Despina Papadopoulou \\ Department of Theoretical and Applied Linguistics, School of English, Aristotle University of Thessaloniki, \\ Thessaloniki, 54 124, Greece
}

Received 8 February 2005; received in revised form 25 July 2005; accepted 28 July 2005

\begin{abstract}
The aim of this study is to investigate the interaction between viewpoint aspect and argument realization. More specifically, we examine the correlation of $+/$-perfective verb forms in Greek and null objects with indefinite, non-specific interpretation. It is argued that although null objects are possible with both perfective and imperfective verbs, imperfective verbs favour object omission more than perfectives. We claim that this is due to two reasons: first, that there is a difference in the syntactic representation of overt direct objects with perfective and imperfective verbs, which is associated with the notion of economy in their respective derivations, i.e. Merge as opposed to Merge + Move; secondly, that perfective verbs show an interpretive difference at the LF interface depending on the overt versus null nature of the direct object, whereas imperfectives do not. The difference is related to the semantic notion of telicity. This prediction has been tested in an off-line sentence-completion task with two groups of native speakers of Greek, an adult and a child group. The data revealed that native speakers of Greek preferred to use overt DP objects with perfective verbs more than with imperfectives. This finding is interpreted as showing that Aspect is a functional feature with an effect on argument realization.
\end{abstract}

(C) 2006 Elsevier B.V. All rights reserved.

Keywords: Transitivity; Aspect; Telicity

\section{Introduction}

The role of Aspect in argument structure and argument realisation has been addressed in various studies. Semantically, predicate interpretation involves the interaction of the verb's situation type and the specificity of the direct object (e.g. Smith, 1991). Language-specific

\footnotetext{
* Corresponding author. Tel.: +30 231 0997444; fax: +30 2310997432.

E-mail address: imt@enl.auth.gr (I.M. Tsimpli).
} 
options determine which aspectual notions are grammaticalised, e.g. verbal particles marking +/-telicity (Germanic languages: van Hout, 1992, 1996), morphological marking of +/-perfectivity (Slavic and Balkan languages: Joseph, 1983) or $+/$-progressive (English: Comrie, 1976; Smith, 1990). These options, together with crosslinguistic differences in the syntactic status of arguments (DP or NP), provide a large typology of possible interactions between the category of Aspect and argument structure.

In early generative accounts, argument realisation was determined by lexical information and the operation of UG-Principles such as the Projection Principle and the EPP (Chomsky, 1986). Transitivity of a verb was a property associated with the verb's lexical entry and the Projection Principle ensured that lexical information would be syntactically represented throughout the derivation. In addition, subcategorisation properties would be determined by the lexical entry but were also argued to partly map onto lexical-conceptual representations (cf. Hale and Keyser, 1986; Jackendoff, 1986). Recently, this understanding of argument structure as being lexically determined has been challenged. Hale and Keyser's (1993) proposal is based on the idea that syntax, rather than the lexicon, is responsible for argument realisation as well as for surface differences found in unaccusative, unergative and transitive verbs.

The role of aspect in recent syntactic accounts of argument realisation, involves its syntactic representation as a functional feature or category within the verbal domain (cf. Ritter and Rosen, 1998; Sanz, 2000; Tenny, 1987; Travis, 2000). Aspectual features determine, on their own or in combination with other formal features of the predicate, the realisation and interpretation of subject and object arguments (Arad, 1998; Borer, 1994, 2004; Tenny, 1987). According to Borer's theory of argument structure, event structure is determined by the optional merger of specific functional heads with particular semantic values. For instance, a transitive, telic event involves the "subject", referred to as the [Originator], in the higher functional position EP (Event Phrase), whereas the "object", referred to as the subject-of-quantifiable-change, occupies the lower functional position $\mathrm{ASP}_{\mathrm{Q}}$ (cf. Borer, 1994, 1998, 2004). Differences between telic and atelic transitive predicates are captured by the absence of $\mathrm{ASP}_{\mathrm{Q}}$ in the atelic event. Note that the theory aims to provide a syntax-based combination of aspectual verb meanings and argument realisation. Thus, the semantic/cognitive component of aspectual properties, such as accomplishments, achievements or states, as well as telicity, are argued to be (a) syntactically determined and (b) responsible for argument realisation. In this respect, the theory is neutral with regard to language-specific properties such as the presence or absence of morphologically marked aspectual distinctions, or the type of aspectual features grammaticalised (e.g. perfectivity).

Turning now to null arguments, their availability in particular syntactic contexts has been shown to differ crosslinguistically (cf. Huang, 1984; Rizzi, 1982, 1986, among others). Thus, studies on null arguments suggest parametrically based distinctions in the inflectional properties of the clause which contains a null object and in the status of the null object itself. ${ }^{1}$ With regard to the typology of null objects, the basic considerations concern the presence or absence of an antecedent responsible for the interpretation of the empty category, the nature of the antecedent (in the syntax or in the discourse) and the properties of the VP in which the null object is allowed.

\footnotetext{
${ }^{1}$ PRO is an exception to this generalization, in that its distribution is defined in terms of finiteness (cf. Chomsky and Lasnik, 1993).
} 
The present paper investigates the properties of antecedent-less null objects with non-specific interpretation in Greek, illustrated in (1):
a. Efaghe ke ipje. ate-PERF.3s and drank- PERF.3s
"(S)He ate and drank."
b. Etroghe ke epine.
ate-IMPERF.3s and drank-IMPERF. $3 \mathrm{~s}$
"(S)He was eating and drinking."

We will argue that the morphologically marked aspectual distinction between perfective and imperfective verb forms interacts with the null object option in Greek. More specifically, we will show that this interaction predicts differences in the rate of occurrence of null objects with perfective and imperfective verb forms: with both of these, null objects are acceptable, but they are the preferred option with imperfectives. This prediction was tested with two groups of native speakers of Greek, adults and children.

The structure of the paper is the following: section 2 provides a brief outline of the properties of the Greek aspectual system and its interaction with the interpretation of direct objects. Null objects are discussed in section 3. More specifically, the types of null objects found in Greek are presented in 3.1, whereas in 3.2 we analyse antecedentless null objects, which are the focus of the present study. The syntactic representation of $+/$-perfective optionally transitive verbs and the effects on object drop are discussed in sections 3.3 and 3.4, respectively. The empirical study we conducted is described in section 4. Some concluding remarks are offered in section 5 .

\section{Aspect in Greek}

Aspectual meaning is assumed to provide information about the internal temporal organization of an event. According to Smith (1991), there are two independent aspectual components whose interaction gives rise to the overall aspectual meaning of a given sentence: situation type and viewpoint aspect.

Situation type aspect is conveyed by the lexical meaning of the verb along with the use of certain adverbials such as already, yet, etc. Due to their inherent semantic features, verbs might denote the following basic situation types (Smith, 1991:6, 28-33): states (know the answer), activities (walk in the park), accomplishments (learn Greek), semelfactives (knock), achievements (win the race). Viewpoint aspect is a grammatical category, generally denoted by verbal morphemes or special forms, that refers to the subjective view one can impose on the internal temporal constituency of a certain event. According to Smith (1991:6), there are three main viewpoint aspectual types: perfective, which views the situation as a whole with initial and final points, imperfective, which views part of the situation without initial or final points, and neutral, which includes the initial point of the situation and at least one internal stage.

In Modern Greek, viewpoint aspect is grammaticalised in the verbal system. The distinction between perfective and imperfective viewpoint aspect is indicated morphologically in $+/$-past and the future, as well as in the subjunctive and imperative forms, and it is realized via changes of the stem vowel and/or changes of the final consonant of the verbal stem (Mirambel, 1959). Mozer (1994) points out that the main semantic feature of the perfective is to look at the event structure 
as a whole, whereas imperfective aspect assigns a habitual or continuous interpretation to the predicate.

In Greek, as in other languages, it is the combination of viewpoint aspect and situation type of the verb, together with the presence and the type of complements and adjuncts, which define the aspectual meaning of the predicate (Horrocks and Stavrou, 2003, in press; Sioupi, 2002). Activity verbs, which are the focus of study in this paper, are inherently atelic but acquire a telic interpretation, and therefore, an accomplishment reading, when followed by a specific direct object (cf. Mozer, 1994; Chila-Markopoulou and Mozer, 2001; Sioupi, 2002):
a. Zoghrafise ton/enan pinaka. painted-PERF.3s the/a-ACC picture "(S)he painted a picture."
b. Zoghrafize ton/enan pinaka. painted-IMP.3s the/a- ACC picture "(S)he was painting a picture."

Sentence (2a) is interpreted as telic due to the fact that the boundary imposed by the perfective aspect coincides with the natural endpoint of the activity (see also Horrocks and Stavrou, 2003:292). On the other hand, the predicate in (2b) may be read as atelic and denote an on-going activity or as telic. The latter option becomes available when 'the painting of the picture' is seen as the endpoint of the event, though not completed, or when the predicate has a habitual interpretation (Chila-Markopoulou and Mozer, 2001:141). Furthermore, Chila-Markopoulou and Mozer (2001) point out that predicates consisting of imperfective activity verbs followed by bare nouns, which are non-specific, are atelic and might even denote a permanent property of the subject:

$$
\begin{aligned}
& \text { I Eleni zoghrafize portreta. } \\
& \text { the-NOM Eleni-NOM painted-IMP.3s portraits } \\
& \text { "Eleni was painting portraits." }
\end{aligned}
$$

Perfective activity verbs when combined with bare nouns also assign an atelic reading to the predicate:

$$
\begin{aligned}
& \text { I Eleni zoghrafise portreta. } \\
& \text { the-NOM Eleni painted- PERF.3s portraits } \\
& \text { "Helen painted portraits." }
\end{aligned}
$$

The difference between (3) and (4) is that (4) cannot denote a permanent property of the subject due to the endpoint necessarily implied by the perfective aspect. Notice that the use of perfective forms with some activity verbs is not allowed when the intended meaning is that of a permanent property (the example is from Mozer, 1994:105):

$$
\begin{aligned}
& \text { - Matheno oti iste sindaksiuhos. Ipirksate omos traghudhistis. } \\
& \text { Hear-1s that are-2PL retired-Nom. Were-PERF.2P but singer- NOM } \\
& \text { - Ne, traghudhusa / *traghudhisa. } \\
& \text { Yes, sang- IMP.1s / *sang- PERF.1s } \\
& \text { "- I hear that you are now retired. But you used to be a singer. } \\
& \text { - Yes, I was a singer." }
\end{aligned}
$$


To sup up, the +/-telic reading of predicates is affected by the viewpoint aspect of the verb form as well as the type of its direct object. In sections 3.3 and 3.4, we will examine the interaction between the (im)perfective distinctions and the presence of an overt DP object.

\section{Null objects in Greek}

\subsection{Types of null objects}

Null objects include those with a specific referent introduced in the previous discourse and those without a referent (see also Cummins and Roberge, 2004 for a typology of null objects). In Greek, object arguments with specific interpretation are necessarily overt in sentences with transitive verbs, either as an object clitic or as a full DP. ${ }^{2}$ The similarity between the clitic and $\mathrm{D}$ is that both manifest the verb's transitivity by lexicalising Case (Roussou and Tsimpli, 2006).

Nevertheless, in contexts involving objects with non-specific reference, omission is possible. Specifically, null objects are found in contexts of NP-ellipsis (Giannakidou and Merchant, 1997; Panagiotidis, 2003) where an indefinite antecedent is present in the discourse, but also in contexts where no antecedent is available. The sentence in (6) exemplifies NPellipsis:
A: Efere
0
Andreas
merika vivlia?
B: $\mathrm{Ne},(*$ ta $) \quad$ efere.
A: Brought-2s the-NOM Andreas-NOM some books
B: Yes, (*them)-brought-3s

"A: Has Andreas brought any books? B: Yes, he did."

Note that the presence of an object clitic in (6) results in ungrammaticality. The examples in (7a) and (7b) illustrate environments in which null objects are found with indefinite reference and no antecedent:
a. Kathos dhjavaza, htipise to tilefono.
While was-reading-1s rang-3s the phone
"While I was reading, the phone rang."
b. To kolibi kurazi.
the swimming tires
"Swimming makes you tired."

(7b) is a generic statement, whereas (7a) includes a temporal adjunct clause and the whole sentence is anchored in time. The null objects in (6) and (7) have a shared property, namely an indefinite, non-specific reading. In ( $7 \mathrm{~b})$, the reading obtained is usually the property reading of

\footnotetext{
${ }^{2}$ Object clitics are available even in contexts where the interpretation of the object is that of a variable or a null constant, e.g. in interrogatives, relatives or null operator structures (Tsimpli, 1999). It has been argued that the extensive use of object clitics in Greek is associated with the verb's transitivity, grammaticalised as case on a Clitic Position (Roussou and Tsimpli, 2006). Thus, it appears that Greek generally disallows null objects with a specific reading, unlike languages like Portuguese (Raposo, 1986; Farrell, 1990), French (Cummins and Roberge, 2004 and references therein) and Slavic languages (Kowaluk, 2001).
} 
the syntactic subject and the null object could be analysed as pro arb. This type of null object is also found in English generic statements (e.g. Smoking kills). ${ }^{3}$

In this paper we focus on null objects such as the one in (7a). In the following section, we will discuss this type of empty category, found in contexts where no antecedent is available and associated with an indefinite/non-specific interpretation.

\subsection{Antecedentless null objects}

Object omission with some transitive verbs is attested in many languages, including English and Greek. For example, verbs like eat, drink, and cook can be used without an overt object, whereas verbs like devour, destroy, and build disallow object omission, at least in English:
a. John ate.
b. John ate a fruit.
a. *John built.
b. John built a hotel.

With regard to examples like (8), it has been argued that object omission affects the situation type of the verb: (8a) denotes an activity, whereas (8b) denotes an accomplishment (Verkuyl, 1993). Object omission is not possible in (9a) because verbs like build denote accomplishments and, therefore, the predicate must be telic. The unavailability of object omission is thus viewed as a consequence of telicity.

More recently a number of studies have argued that argument realization is determined by the situation type of the verb, as this is decomposed into event structure templates (Grimshaw and Vikner, 1993; van Hout, 1996; Rappaport-Hovav and Levin, 1998, 2001; Wright and Levin, 2000). They propose the Argument Realization Principle (ARP) presented in (10):

$$
\begin{aligned}
& \text { ARP: There must be one argument XP in syntax to identify each subevent } \\
& \text { in the event structure template. }
\end{aligned}
$$

One implication of the ARP is that accomplishment verbs such as build would disallow object omission, which is the case for English illustrated in (9a). However, Goldberg (2005) notices two problems with the ARP: the first is that there are cross-linguistic differences in argument realization (see also the Greek examples (11) and (12)) and the second is that, even in English, the arguments of certain multiple-event verbs might be omitted (cf. Bill cried into the paper bag).

\footnotetext{
${ }^{3}$ There are constraints on both the type of verb and the subject involved in generic statements with null objects, such as (7b). For example, in Greek the verb usually belongs to the psychological class and the subject is its cause argument. In these cases, the object is a null experiencer with [+human], [+arbitrary] reference:

(i) a. To dhjavasma ksekurazi.

The-NOM reading-NOM relaxes

"Reading relaxes you."

b. I tenies tu Hitchcock sinarpazun.

The-NOM films-NOM the-GEN Hitchcock fascinate

"Hitchcock's films fascinate people."

c. I istories me fadasmata fovizun.

the-NOM stories-NOM with ghosts scare

"Stories with ghosts scare people."
} 
Goldberg proposes certain constraints motivated by discourse pragmatics to explain counterexamples to the ARP.

Turning to the Greek data, we observe that object drop is more productive than in English and possible even with verbs expressing accomplishments:

$$
\text { O Petros ehtise sti Halkidhiki. }
$$

the-NOM Petros-NOM built-PERF-3s in-the Halkidhiki "??Petros built in Halkidiki."

$$
\begin{aligned}
& \text { I ehthri katestrepsan ki ekapsan. } \\
& \text { the-NOM enemies-NOM destroyed-3P and burnt-3P } \\
& \text { "*The enemies destroyed and burnt." }
\end{aligned}
$$

Note that the Greek data in (11) and (12) involve verbs marked for perfective aspect. However, object drop is possible and, for most speakers preferred, with imperfective verbs:

$$
\text { O Petros ehtize sti Halkidhiki. }
$$

the-NOM Petros-NOM built-IMP.3s in-the Halkidhiki

"??Petros was building in Halkidiki."

$$
\begin{aligned}
& \text { I ehthri katestrefan ki ekeghan. } \\
& \text { the-NOM enemies-NOM destroyed-IMP.3P and burnt-IMP.3P } \\
& \text { "*The enemies were destroying and burning." }
\end{aligned}
$$

The perfective/imperfective distinction has been shown to affect object drop in other languages too. Babko-Malaya (1999) shows that, in Russian, null objects are allowed in sentences with imperfective un-prefixed verbs but not with perfective ones:
a. Ivan pisal.
Ivan wrote-IMP
"Ivan was writing."
b. Ivan pisal pis'mo.
Ivan wrote-IMP letter-ACC
"Ivan was writing a letter."
a. *Ivan napisal
Ivan PERF-wrote
"Ivan wrote."
b. Ivan napisal pis'mo.
Ivan PERF-wrote letter-ACC
"Ivan wrote a letter."

The analysis proposed by Babko-Malaya suggests that the overt object is an argument of the perfectivizing prefix. The prefix forms a predication relation with the object and requires it to be overt.

The grammaticality of the Greek examples in (11) and (12) shows that the Russian asymmetry illustrated in (15) and (16) is not attested in Greek. In other words, there is no grammaticality effect depending on the perfective/imperfective distinction. Note, however, that the aspectual 
distinctions shown in the Russian examples are assumed to be part of derivational morphology in that the perfectivizing prefix is attached to the verb pre-syntactically (Babko-Malaya, 1999; Dahl, 1985). Greek aspectual distinctions, on the other hand, do not involve prefixation. Instead, they are grammaticalised and marked on the verbal stem, as inflectional morphemes (see section 2$)^{4}$

Even though aspectual differences in Greek do not affect the grammaticality of object omission, they might change the situation type of activity verbs. Specifically, a predicate involving a perfective activity verb and an overt DP object acquires an accomplishment reading, whereas the same verb form with a null object denotes an activity (cf. Mozer, 1994 and section 2):
a. $\quad$ Eghrapse. / Eghrafe.
wrote-PERF / Wrote- IMP
"(S)He wrote. / (S)He was writing."
b. Eghrafe ena/to arthro.
wrote-IMP a/the paper
"(S)He was writing a/the paper."
c. Egrapse ena/to arthro.
wrote-PERF a/the paper
"(S)He wrote a/the paper."

In (17c), the combination of perfectivity with an overt DP object renders the predicate necessarily telic, implying that the event is complete. No such reading is available in (17a) where the object is null and the verb + or - perfective. In (17b), where the verb is imperfective and the DP object overt, the predicate might be atelic, ${ }^{5}$ in the sense that the sentence denotes an on-going activity with an arbitrary final point (cf. Smith, 1991:29). These interpretative options are summarized in $(18 \mathrm{a}-\mathrm{d})$ :

$$
\begin{array}{llll}
\text { a. } & \text { +perfective, overt object (DP) } & \Rightarrow & \text { +telic } \\
\text { b. } & \text { +perfective, null object } & \Rightarrow & \text {-telic } \\
\text { c. } & \text {-perfective, overt object (DP) } & \Rightarrow & \text {-telic } \\
\text { d. } & \text {-perfective, null object } & \Rightarrow & \text {-telic }
\end{array}
$$

In (18b) and (18d), the verb event is highlighted and the null object is a non-individuated noun. Bare nouns in object position are also non-individuated in that they are not identified as referential entities and behave as predicate modifiers (van Hout, 1992; Sioupi, 2002):
a. Majireve psari / psarja. cooked-IMP.3s fish-SG / fish-PL "(S)He was cooking fish"
b. $\quad$ Majirepse psari / psarja. cooked-IMP.3s fish- SG / fish- PL "(S)He cooked fish."

\footnotetext{
${ }^{4}$ It has independently been argued that the Greek aspectual system is similar to that of the Southern Slavic languages, but not that of Eastern Slavic (Tsangalidis, 1999).

${ }^{5}$ Notice that the predicate might also be telic when the sentence denotes a habitual action.
} 
Neither (19a) nor (19b) denote telic events. The difference between them is the visibility of an endpoint in (19b), where the verb is morphologically marked for perfectivity. The representation of the object in (19) is a bare $\mathrm{N}$ with no D element (Cummins and Roberge, 2004; Hopper and Thompson, 1980; cf. Sioupi, $2002^{6}$ ).

\subsection{The syntactic representation of optionally transitive verbs}

Before addressing the contrast between null (non-individuated) and overt DP objects, a basic question concerning structures such as $(17 \mathrm{a}-\mathrm{c})$ is the syntactic representation of optionally transitive verbs like ghrafo 'write'. We assume following Hale and Keyser $(1993,2002)$ that transitivity is a syntactic requirement in that all verbs are represented as having a direct object position. Thus, (17a) includes a direct object position, just like (17b) and (17c), albeit with a "cognate", indefinite, non-specific object (Chomsky, 1986; Cummins and Roberge, 2004; Roberge, 2002). The variability shown in the overt versus null choice of the direct object is sensitive to syntactic, semantic and pragmatic constraints (see also Goldberg, 2005).

More specifically, we adopt the Transitivity Requirement (TR), which reads as in (20) (cf. Basilico, 1998; Bowers, 2002; Erteschik-Shir and Rapoport, 2004; Hale and Keyser, 1993; Pirvulescu and Roberge, 1999; Roberge, 2002):

a. Transitivity Requirement (TR): An Obj position is always included in VP, independently of lexical choice of $\mathrm{V}$.

b.

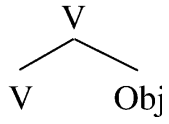

Roberge (2002) argues that TR is the direct object counterpart to the EPP. Crucially, TR is assumed to be the subcategorisation requirement of the verb, to be kept distinct from $\theta$-marking, which involves both the (object) position and the category (Chomsky, 1981). TR dictates the representation of a TransP, that is, a phrase headed by the functional head Trans (Basilico, 1998; Bowers, 2002). SpecTrans is the EPP position for direct objects, where Case is checked (Bowers, 2002).

In Basilico's account, the interpretive differences between predicates focusing on the verb event and predicates with individuated objects is reflected in the syntactic representation of direct objects. In particular, individuated objects are merged in SpecTransP whereas non-individuated ones are merged in the lower VP. ${ }^{7}$ Adopting this distinction, we also argue that Trans bears aspectual features, which are grammaticalised in Greek. In other words, we propose that the perfective/imperfective distinction is realized as a formal feature on Trans (cf. Arad, 1998; Borer, 1994, 2004, 2005; Tenny, 1987). Aspect is thus associated with the syntactic realization of TR, and has effects on argument realization: the DP direct object of a Trans ${ }_{[+ \text {perf] }}$ and a Trans ${ }_{[+i m p e r f]}$

\footnotetext{
${ }^{6}$ Sioupi (2002) suggests that the structure in this case includes a null D, on the assumption that syntactic arguments always project as DPs.

${ }^{7}$ Basilico distinguishes between thetic and categorical predicates (cf. Kuroda, 1972; Milsark, 1974; Ladusaw, 1994) to refer to sentences with emphasis on the verb event alone and on the verb event together with the direct object, respectively. One anonymous reviewer brought to our attention that this distinction was originally proposed to capture different phenomena. For this reason, we will set these terms aside and we use the terms 'individuated object' for predicates whose interpretation focuses both on the verb event and the direct object, on one hand, and 'non-individuated object' for predicate interpretation including the verb event alone, on the other.
} 
verb have different base-generated positions. The DP object of a Trans ${ }_{[+ \text {perf] }}$ verb is merged in SpecTransP, whereas the DP object of a Trans ${ }_{[+ \text {imperf] }}$ verb is merged in the lower VP. Movement of the direct object from the specifier position of the lower VP to specTransP is necessary for Case reasons (see (21) and (22), respectively). This difference in the merge position of direct objects is associated with the telic versus atelic interpretation of the perfective and imperfective predicates respectively. Specifically, individuated objects of imperfective predicates always give rise to an atelic interpretation, whereas predicate interpretation of perfective verbs with individuated objects is telic.

(21)

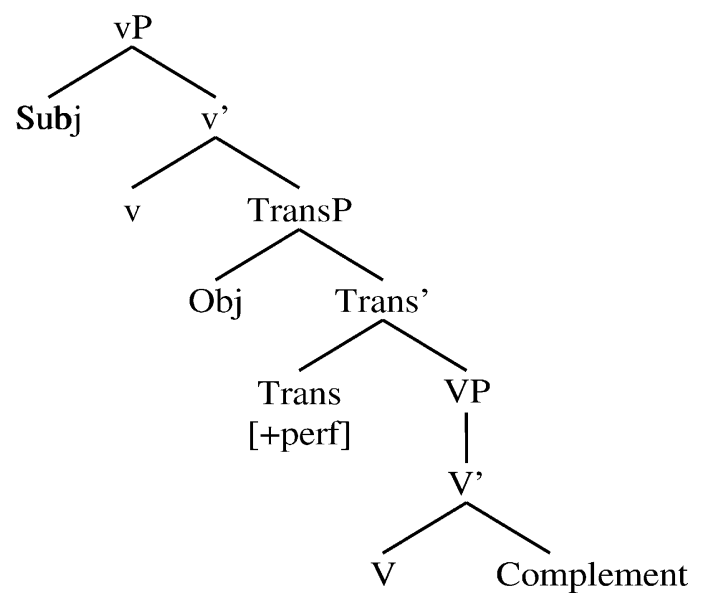

(22)

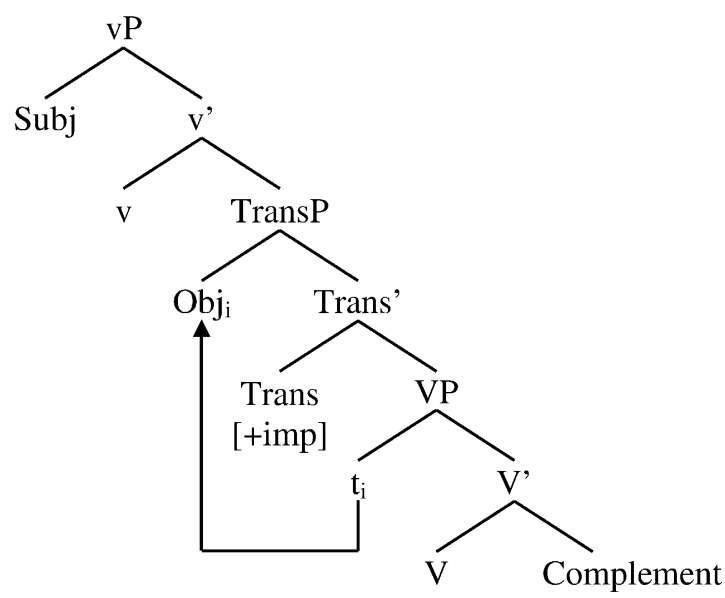

With respect to structures involving null, i.e. non-individuated, objects (18b) and (18d), the predicate interpretation is atelic irrespectively of the aspectual form of the verb. It could then be argued that verbs with null objects are represented according to the structure shown in (22), irrespectively of the aspectual feature on Trans. Recall that bare nouns in object position, similarly with null objects, attribute an atelic predicate reading regardless of the aspectual verb form. "Cognate" null objects in structures like (17a) are non-referential and have the internal 
structure of bare nouns with a null N (see also Cummins and Roberge, 2004). Recall that argument licensing in Greek is mediated by the Case feature realized as a lexicalised D (Roussou and Tsimpli, 2006). In the case of null objects, the Case requirement is relaxed, given that they are empty categories with no D element, and movement of the object to specTransP, is unmotivated. The relevant structures are presented below:

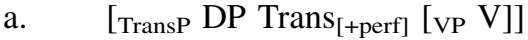

$$
\begin{aligned}
& \text { b. } \quad\left[\text { TransP } \operatorname{Trans}_{[+ \text {perf }]}\left[\mathrm{VP}\left[{ }_{\mathrm{N}} \emptyset\right] \mathrm{V}\right]\right] \\
& \text { a. [TransP DP Trans }[- \text { perf }] \text { [VP } Đ P \text { V }]] \\
& \text { b. } \quad\left[\text { TransP } \operatorname{Trans}_{[-\operatorname{perf}]}[\mathrm{VP}[\mathrm{N} \emptyset] \mathrm{V}]\right]
\end{aligned}
$$

\author{
Perfective + Direct Object \\ Perfective + Null Object \\ Imperfective + Direct Object \\ Imperfective + Null Object
}

\subsection{Consequences for object drop}

On the basis of the structures in (21) and (22), our prediction is that although both aspectual forms allow object omission, and, hence, no grammaticality issue arises, the differences in the syntactic representation and the interface interpretation of perfective and imperfective structures with null/overt objects, will result in a preference for null objects with imperfectives.

This prediction is partly based on the Merge + Move versus Merge option for the overt direct object: Both Merge and Move are required with Trans $\mathrm{P}_{[+ \text {imperf] }}$ whereas only Merge is needed with Trans $\mathrm{P}_{[+ \text {perf]. }}$. The two options for the overt object in perfective and imperfective structures, respectively, do not necessarily explain why there should be an LF difference, if the resulting syntactic representation appears identical (in both cases the direct object is in specTransP). We assume that the interpretation of the event as atelic or telic is determined at the LF interface, on the basis of the chain formed in each case (Brody, 1995; Chomsky, 1986): in imperfective structures a chain with two copies, one in the lower VP and one in specTrans is involved, whereas in perfective structures a single copy is found in specTrans (by Merge).

Concentrating on the null/overt object option with perfective verbs, they involve Merge of the object in the VP and the TransP, respectively. The resulting predicate interpretation is different: telic with an overt DP object and atelic with a null object. ${ }^{8}$ The interpretive differences between the atelic and the telic readings with perfective verbs are thus accounted for. Considering imperfective verb forms, overt and null objects are merged in the lower VP and the overt DP object raises to specTrans. However, the overt object option does not change the atelic reading at the interface, while at the same time it involves an additional syntactic operation (Move). We could argue that (24a) is the least preferred structure, as it involves an additional syntactic operation with no interpretive effects. These predictions have been tested in a paper-and-pencil sentence-completion task, which is presented in the next section.

\section{The sentence-completion task}

The purpose of the sentence-completion task was to examine native speakers' preferences with respect to argument realisation and verbal aspect. ${ }^{9}$ More specifically, our hypothesis is that

\footnotetext{
${ }^{8}$ If a null object was merged in specTransP, the derivation would crash due to the lack of D, the category responsible for Case. For the same reason, bare $\mathrm{N}$ should also merge in the lower VP position.

${ }^{9}$ For the correlation between transitivity and telicity in adult and child Dutch see van Hout (1997) and Thrift and Hyams (2001). For the acquisition of the verb's telicity markers see Schulz and Wittek (2003) and Schulz et al. (2001).
} 
native speakers of Greek will exhibit a preference to use null rather than overt objects with imperfective verb forms due to the absence of telicity differences in combination with the requirement of the raising of the overt object.

The subjects were presented with written sentence fragments including the verbs under investigation and their task was to complete the sentences by writing appropriate continuations. This was an off-line task and there were no time constraints on the completion of the task, even though the subjects were instructed to continue the sentences in a natural and spontaneous way and as fast as possible.

The participants of this study belong to two groups, Greek adults and 10- to 11-year-old children. The choice of the two groups was not motivated by any developmental assumptions regarding grammar-based differences, given that the competence of children of this age is adultlike. However, given that the task attempts to tap into differences in preferences rather than in (un)grammatical choices, the child group may differ from the adult group due to semantic or pragmatic effects on argument realization. For example, Traxler's (2002) study on ambiguity resolution with English adults and 10- to 11-year-old children revealed significant differences between the two groups. In particular, children were more likely to violate pragmatic considerations in on-line sentence processing. In addition, our choice for relatively old children was motivated by the written nature of the task, which requires good reading and writing abilities.

\subsection{Method}

\subsubsection{Materials}

The materials consisted of 66 sentence fragments, which included a temporal subordinating connective and a verb, illustrated in (27):
a. Kathos etrehe /etroje ............ while ran-IMP.3s / ate-IMP.3s
"While (s)he was running / eating ..............
b. Afu etrekse / efaghe ....
while ran-PERF.3s / ate-PERF.3s
"After (s)he ran / ate ..."

The critical items consisted of 22 optionally transitive verbs, all of which denote activities. We also included eleven intransitive verbs for control purposes. Specifically, we wanted to establish that both groups, but especially the child group, were sensitive to subcategorisation properties. These 33 verbs were presented in two aspectual forms, the perfective and the imperfective. All verbs were in the 3rd person singular and marked for [+past] tense. The temporal connectives used with perfective verbs were: otan 'when', molis 'as soon as', afu 'after'; with imperfective verbs: eno 'while', tin ora pu 'while' (lit. 'the time that'), osin ora 'while' (lit. 'as-much time'), kathos 'while'.

\subsubsection{Procedure}

The 66 sentence fragments were divided into two versions, each consisting of the same 33 verbs so that each version included both perfective and imperfective verb forms but not both aspectual forms of the same verb. Thus, for example, version A would include the form efaghe 
(= ate-PERF) and version B the form etroghe (= ate-IMP). All subjects were exposed to both aspectual forms but none saw the same verb form more than once.

Each version of the questionnaire was presented in a booklet and each sentence fragment was printed on a separate sheet of paper. The instructions were typed on the first sheet of each booklet and requested from the subjects to write appropriate continuations which would result in wellformed sentences.

\subsubsection{Participants}

Seventy-four native speakers of Greek participated in the study, 36 adults and 37 children. They were all monolingual speakers of Greek and naïve with respect to the purpose of the experiment. The mean age of the adult participants was 32;18 years (age range: 18-65) and there were 19 males and 17 females. The children were all attending the 6th grade of primary school and their age range was from 10;6 to 11;6 years. There were 18 boys and 19 girls.

\subsection{Results}

The data analysis consisted in counting the frequencies of overt direct objects (transitive uses) and null objects (intransitive uses) for each verb in both the perfective and the imperfective form. It is noteworthy that there were no ungrammatical sentences produced either by the adults or by the children with the exception of the verb htenizo 'comb' in the child data. ${ }^{10}$

The initial counts were carried out for both the critical (i.e. optionally transitive verbs) and the control items (i.e. prototypically intransitive verbs). Starting with the control verbs, a close item-by-item analysis revealed that seven of the 11 intransitive verbs were never followed by a direct object in the data of either group: vixo 'cough', lipo 'be absent', ghelo 'laugh', kleo 'cry', vafome 'paint oneself; be painted', kimame 'sleep' and plenome 'wash oneself; to be washed'. This result shows that the subcategorisation properties of the verbs are observed by all subjects. The above-mentioned intransitive verbs were excluded from any additional analyses reported below for both the adult and the child data. The remaining four control verbs, namely treho 'run', perpato 'walk', horevo 'dance' and kolimbo 'swim', were occasionally

\footnotetext{
${ }^{10}$ The verb htenizo was the only one that elicited a $36.8 \%$ of ungrammatical sentences in the child data. The ungrammaticality of these sentences consists in the use of this verb as intransitive active, as well as with a reflexive interpretation. The intransitive active reading is marked and used only in contexts where one is a hairdresser and 'combs' by profession. This marked interpretation could only be associated with one or two of the children's intransitive uses of this verb. In the rest of the cases, children use this verb with the reflexive interpretation, and non-target voice morphology. In adult Greek the reflexive meaning requires the non-active form htenizome 'to brush one's own hair'. Examples of the ungrammatical sentences produced by the children are provided below:

(i) a. *Otan htenise efighe apo to spiti.

when brushed- PRF.3s left-3s from the house

"*When (s)he brushed, she left the house."

b. *Eno xtenize, vrike mia psira.

while combed-IMP.3 s found- PERF.3 s one lice

"*While (s)he was combing, (s)he found a lice."

We assume that the unexpectedly high level of ungrammatical sentences with this verb in the child data could be related to the 'reduction' of non-active voice morphology marked on this verb. This process is possible with a large number of ergative verbs in Greek (e.g. 'crinkle', 'get-dirty', 'zip', 'unzip', etc.) which show optionality in the use of active and nonactive morphology. The reflexive reading, however, resists this optionality and requires non-active voice morphology in all cases.
} 
produced with direct objects and, consequently, they were included in the analyses for the critical items.

Turning to the critical items, from the total of the 22 optionally transitive verbs tested, only one, namely the verb htenizo 'comb', was always used by the adults, but not by the children, as transitive in both aspectual forms; hence, this verb was excluded from the adult data. Thus, the statistical analyses reported below were conducted on 25 verbs ( 21 critical and 4 control verbs) for the adults and on 26 verbs (22 critical and 4 control verbs) for the children.

The mean percentages of verb + overt direct object (transitive) and verb + null object (intransitive) are presented in Fig. 1 for perfective and imperfective verb forms per group.

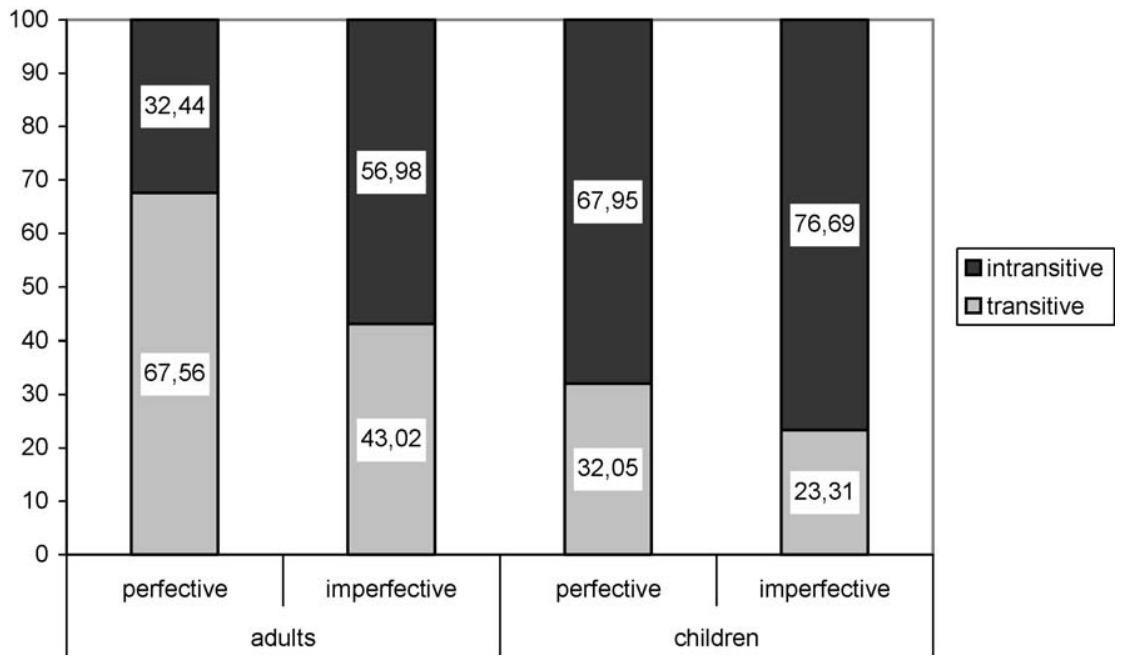

Fig. 1. Mean percentages of transitive and intransitive uses for the perfective and the imperfective verb forms.

The percentages reported in Fig. 1 clearly show that in both groups, adults and children, the rate of production of overt or null objects was affected by the aspectual form of the verb. Specifically, perfective verb forms favour the transitive structure, whereas imperfectives favour the intransitive. This observation was statistically supported by a one-way repeated measures ANOVA with Aspect (perfective versus imperfective) as the within-subject/item variable. The main effect of Aspect was significant for both groups (adults: $F 1(1,35)=30.485, p<0.001$; $F 2(1,24)=33.947, \quad p<0.001 ; \quad$ children: $F 1(1,36)=9.867, \quad p<0.01 ; \quad F 2(1,25)=7.866$, $\left.p<0.02^{11}\right)$.

We further tested whether this effect was evident with all verbs. The adult and child percentages of transitive and intransitive uses for each verb in its perfective and imperfective form can be found in Tables A.1 and A.2 of Appendix A, respectively. Chi-square tests were performed per each verb in order to establish whether there is a correlation between Transitivity and Aspect. In the adult data, 16 of the verbs exhibited a significant correlation (zografizo 'paint', ghrafo 'write', ravo 'sew', pino 'drink', vafo 'paint', sprohno 'push', horevo 'dance', treho 'run', traghudho 'sing', pleno 'wash', psino 'roast', perpato 'walk', shedhiazo 'sketch', dhjorthono

${ }^{11} \mathrm{~F} 1$ represents the statistical analysis for the subjects and F2 the analysis per item. 
'mark', dhjavazo 'read', kinigho 'hunt') and for the verb randizo 'spray' this effect was marginally significant. The values of the Chi-square tests per verb in each participant group can be found in Appendix B. Eight verbs did not show this effect, although they exhibited a tendency to appear as transitive with perfective forms more often than with imperfectives (see Appendix A). The child data manifested that the correlation between Aspect and Transitivity was significant for eight verbs (aplono 'hang our to dry', shedhiazo 'scetch', hereto 'greet', katharizo 'clean', treho 'run', dhjavazo 'read', kitao 'look/stare', troo 'eat') and for four verbs (ravo 'sew', randizo 'spray', kinigho 'hunt', horevo 'dance') the effect was marginally significant. The remaining verbs were preferred as intransitive, irrespective of their aspect (see Appendix A for the entire list).

The adult and the child data differed in the overall preference for transitive over intransitive structures. Specifically, the adults had a preference for the production of transitive structures, whereas the children exhibit the opposite pattern. A one-way repeated measures ANOVA with Subcategorization (transitive versus intransitive) as the within-subject/item variable was conducted on the subjects' responses across perfective and imperfective aspect. The differences between the transitive and the intransitive responses were indeed statistically significant for both groups, even though the item analysis in the adult data did not reach significance (adults: $F 1(1,35)=13.845, \quad p<0.01 ; \quad F 2(1,24)=2.620, \quad p=0.119 ; \quad$ children: $F 1(1,36)=23.324$, $p<0.001 ; F 2(1,25)=29.739, p<0.001)$.

\subsection{Discussion}

The sentence-completion task ${ }^{12}$ revealed that the aspectual form of the verb affected the use of null objects: imperfective verb forms were more frequently used with null objects than perfective verbs. This finding, obtained both from the adults and the children, verifies our prediction that intransitive uses of imperfective verb forms are preferred over those of perfectives. The prediction was based on syntactic and interface differences between perfective and imperfective verbs with overt objects. Syntactically, the Merge/Merge + Move distinction in the derivation of overt objects with perfectives and imperfectives, respectively, was argued to give rise to an economy effect favouring the intransitive uses of imperfectives. This preference is further supported by the associated effects on predicate interpretation (telic versus atelic reading) at the interface, which characterize perfective and not imperfective predicates. In addition, the fact that perfective verbs were more frequently used as transitive than imperfective verbs might also be due to the fact that perfectivity is understood as involving an endpoint and the use of an overt object makes this endpoint visible and the sentence more natural (cf. Horrocks and Stavrou, 2003).

Two additional points require some discussion. The first concerns the attested difference between adults and children with respect to the overall preference for transitive and

\footnotetext{
${ }^{12}$ With respect to the seven control verbs which were always used intransitively and as a result were excluded from our analyses, we note that a problem potentially arises with regard to TR. However, we would like to point out that the verbs vafome 'paint oneself; be painted' and plenome 'wash oneself; be washed' are marked for non-active voice morphology. Their intransitive uses are, therefore, due to voice morphology which is known to affect object realisation crosslinguistically. The verbs vixo 'cough', ghelo 'laugh', kleo 'cry' and kimame 'sleep' do accept an overt direct object of the cognate type. In this respect, they are consistent with TR (cf. Roberge, 2002). The fact that our participants did not produce any transitive uses with these verbs is probably due to the 'markedness' of sentences with cognate objects, in the sense that cognate objects do not contribute to the informational content of the sentence. Finally, lipo 'be absent' belongs to the unaccusative verb class and the single (internal) argument appears in subject position. Overall, then, the 'intransitive' use of the above verbs does not constitute counterevidence to TR.
} 
intransitive uses, respectively (overall percentages of transitive uses: children 27.68\%; adults $55.29 \%$ ). In order to address this issue, it is important to recall that null cognate objects are grammatically possible with perfective and imperfective verb forms. Therefore, the difference between children and adults in null object use could be attributed to semantic/pragmatic considerations. One possibility is that the type of structure tested in our study was biased towards a verb event reading. In particular, the sentence fragments we presented our subjects with (While (s)he was eating... / After (s)he ate ...) requires a process of anchoring the temporal structure of this clause with the matrix one. This involves the association of $S($ peech)/R(eference)/E(vent) points between the adjunct and the main clause (cf. Hornstein, 1990). It is then possible that the strong intransitive preference found in the child data is at least partly due to the emphasis on the temporal relation between the two events. An implication of this bias is that an explicit object would shift their attention from the temporal linking between the two clauses to the internal structure of the sub-event.

The final point concerns the variation found in the set of verbs included in the test with respect to the association between transitivity and aspect. In particular, there are verbs which did not show this effect, because they were mostly used either as transitive or as intransitive, irrespective of aspect. The fact remains that the verbal aspect affected object drop in both groups; this implies that even for the individual verbs where no interaction was obtained the tendency to favour transitive structures with perfective verbs was present. We can, then, safely conclude that perfectivity induces the use of DP objects, which results in telic readings. Therefore, the attested variation with individual verbs might be the effect of extra-linguistic factors, such as pragmatic preferences and frequency records of individual verbs.

\section{Concluding remarks}

The theoretical analysis and the empirical study presented aimed at investigating the role of grammatical aspect on transitivity in Greek. We proposed that preferences for overt objects with perfective verbs compared to imperfectives are due to differences in the syntactic representation of overt objects and the effect on predicate interpretation in each case. The analysis presupposes that aspect is syntactically represented as a feature on the functional head Trans, which in turn realizes TR. The empirical study confirmed the predictions of this analysis. Note that, although the analysis is restricted to Greek, it is possible that a correlation between other aspectual distinctions, like situation type or $+/$-progressive viewpoint aspect, and argument realization is present in other languages as well. This is based on the assumption that aspectual properties, which are not necessarily morphologically marked, are syntactically relevant and crucial for argument realization (cf. Borer, 1994, 2004, 2005).

\section{Acknowledgements}

As this issue is dedicated to Neil Smith's long and invaluable contribution to academia, we feel honoured that our paper is included. Neil has been Ianthi Tsimpli's tutor, mentor, co-author and close friend for more than 15 years. His unusual breadth of knowledge in theoretical linguistics, language acquisition and human cognition has enlightened many of his students and colleagues: Ianthi has had the privilege of benefiting long-term from Neil's knowledge, support and criticism for which she is deeply indebted.

We would like to thank Hans van de Koot and two anonymous reviewers for their helpful comments and suggestions on an earlier version of this paper. 


\section{Appendix A}

See Tables A.1 and A.2.

Table A.1

Adults: Mean percentages of transitive and intransitive used per perfective and imperfective verb form

\begin{tabular}{|c|c|c|c|c|}
\hline \multirow[t]{2}{*}{ Verbs } & \multicolumn{2}{|l|}{ Perfective } & \multicolumn{2}{|c|}{ Imperfective } \\
\hline & Transitive & Intransitive & Transitive & Intransitive \\
\hline zoghrafizo 'paint' & 94.44 & 5.56 & 16.67 & 83.33 \\
\hline ghrafo 'write' & 88.89 & 11.11 & 16.67 & 83.33 \\
\hline ravo 'sew' & 83.33 & 16.67 & 11.76 & 88.24 \\
\hline pino 'drink' & 88.89 & 11.11 & 31.25 & 68.75 \\
\hline vafo 'paint' & 88.89 & 11.11 & 33.33 & 66.67 \\
\hline sprohno 'push' & 94.44 & 5.56 & 50 & 50 \\
\hline horevo 'dance' & 38.89 & 61.11 & 0 & 100 \\
\hline treho 'run' & 33.33 & 66.67 & 0 & 100 \\
\hline traghudho 'sing' & 44.44 & 55.56 & 5.56 & 94.44 \\
\hline pleno 'wash' & 100 & 0 & 77.78 & 22.22 \\
\hline psino 'roast' & 100 & 0 & 83.33 & 16.67 \\
\hline perpato 'walk' & 16.67 & 83.33 & 0 & 100 \\
\hline shediazo 'design' & 95 & 5 & 80 & 20 \\
\hline diorthono 'mark' & 94.44 & 5.56 & 77.78 & 22.22 \\
\hline diavazo 'read' & 76.47 & 23.53 & 55.56 & 44.44 \\
\hline kinigho 'hunt' & 88.89 & 11.11 & 72.22 & 27.78 \\
\hline randizo 'spray' & 76.47 & 23.53 & 61.11 & 38.89 \\
\hline aplono 'hang' & 94.44 & 5.56 & 83.33 & 16.67 \\
\hline hereto 'greet' & 83.33 & 16.67 & 72.22 & 27.78 \\
\hline katharizo 'clean' & 83.33 & 16.67 & 77.78 & 22.22 \\
\hline kitao 'stare' & 77.78 & 22.22 & 72.22 & 27.78 \\
\hline kolimbo 'swim' & 5.56 & 94.44 & 0 & 100 \\
\hline troo 'eat' & 33.33 & 66.67 & 22.22 & 77.78 \\
\hline majirevo 'cook' & 5.56 & 94.44 & 11.11 & 88.89 \\
\hline xazevo 'wander' & 27.78 & 72.22 & 25 & 75 \\
\hline
\end{tabular}

Table A.2

Children: Mean percentages of transitive and intransitive used per perfective and imperfective verb form

\begin{tabular}{llllc}
\hline Verbs & Perfective & & \multicolumn{2}{c}{ Imperfective } \\
\cline { 2 - 3 } \cline { 4 - 5 } & Transitive & Intransitive & Transitive & Intransitive \\
\hline aplono 'hang' & 80 & 20 & 33.33 & 66.67 \\
shedhiazo 'design' & 60 & 40 & 22.22 & 77.78 \\
hereto 'greet' & 55 & 45 & 22.22 & 77.78 \\
katharizo 'clean' & 33.33 & 66.67 & 10 & 90 \\
trexo 'run' & 11.11 & 88.89 & 0 & 100 \\
dhjavazo 'read' & 27.78 & 72.22 & 10 & 90 \\
kitao 'stare' & 42.11 & 57.89 & 22.22 & 77.78 \\
troo 'eat' & 5.56 & 94.44 & 20 & 80 \\
ravo 'sew' & 38.89 & 61.11 & 20 & 80 \\
randizo 'spray' & 55 & 45 & 37.5 & 62.5 \\
kinigho 'hunt' & 50 & 50 & 33.33 & 66.67 \\
horevo 'dance' & 5 & 95 & 0 & 100
\end{tabular}


Table A.2 (Continued)

\begin{tabular}{lllll}
\hline Verbs & Perfective & & Imperfective \\
\cline { 2 - 4 } & Transitive & Intransitive & Transitive & Intransitive \\
\hline psino 'roast' & 55 & 45 & 38.89 & 61.11 \\
pino 'drink' & 22.22 & 77.78 & 36.84 & 63.16 \\
zoghrafizo 'paint' & 15.79 & 84.21 & 27.78 & 72.22 \\
ghrafo 'write' & 30 & 70 & 22.22 & 77.78 \\
htenizo 'comb' & 50 & 50 & 45 & 55 \\
sprohno 'push' & 58.82 & 41.18 & 55 & 45 \\
vafo 'paint' & 31.58 & 68.42 & 27.78 & 72.22 \\
hazevo 'wander' & 10 & 90 & 11.11 & 88.89 \\
pleno 'wash' & 38.89 & 61.11 & 40 & 60 \\
maghirevo 'cook' & 11.11 & 88.89 & 10.53 & 89.47 \\
dhjorthono 'mark' & 44.44 & 55.56 & 45 & 55 \\
traghudho 'sing' & 0 & 100 & 0 & 100 \\
kolimbo 'swim' & 0 & 100 & 0 & 100 \\
perpato 'walk' & 0 & 100 & 0 & 100 \\
\hline
\end{tabular}

\section{Appendix B}

Chi-square tests for individual verbs:

\section{Adult data}

zografizo 'paint' $\left(\mathrm{X}^{2}=61.455 ; p<0.001\right)$

ghrafo 'write' $\left(\mathrm{X}^{2}=51.923 ; p<0.001\right)$

ravo 'sew' $\left(\mathrm{X}^{2}=50.125 ; p<0.001\right)$

pino 'drink' $\left(\mathrm{X}^{2}=34.068 ; p<0.001\right)$

vafo 'paint' $\left(\mathrm{X}^{2}=30.643 ; p<0.001\right)$

sprohno 'push' $\left(\mathrm{X}^{2}=24.008 ; p<0.001\right)$

horevo 'dance' $\left(\mathrm{X}^{2}=23.457 ; p<0.001\right)$

trexo 'run' $\left(\mathrm{X}^{2}=20.482 ; p<0.001\right)$

traghudho 'sing' $\left(\mathrm{X}^{2}=19.253 ; p<0.001\right)$

pleno 'wash' $\left(\mathrm{X}^{2}=12.360 ; p<0.001\right)$

psino 'roast' $\left(\mathrm{X}^{2}=8.696 ; p<0.01\right)$

perpato 'walk' $\left(\mathrm{X}^{2}=8.696 ; p<0.01\right)$

shedhiazo 'sketch' $\left(\mathrm{X}^{2}=5.697 ; p<0.02\right)$

dhjorthono 'mark' $\left(\mathrm{X}^{2}=5.316 ; p=0.021\right)$

dhjavazo 'read' $\left(\mathrm{X}^{2}=5.053 ; p<0.03\right)$

kinigho 'hunt' $\left(\mathrm{X}^{2}=4.000 ; p<0.05\right)$

randizo 'spray' $\left(\mathrm{X}^{2}=3.054 ; p=0.081\right.$

aplono '?' $\left(\mathrm{X}^{2}=2.554 ; p=0.110\right)$

hereto 'greet' $\left(\mathrm{X}^{2}=2.098 ; p=0.148\right)$

katharizo 'clean' $\left(\mathrm{X}^{2}=0.585 ; p=0.444\right)$

kitao 'look' or 'stare' $\left(\mathrm{X}^{2}=0.480 ; p=0.488\right)$

kolimbo 'swim' $\left(\mathrm{X}^{2}=3.093 ; p=0.079\right)$

troo 'eat' $\left(\mathrm{X}^{2}=1.786 ; p=0.181\right)$

majirevo 'cook' $\left(\mathrm{X}^{2}=1.099 ; p=0.295\right)$

xazevo 'wander around' $\left(\mathrm{X}^{2}=0.097 ; p=0.755\right)$ 


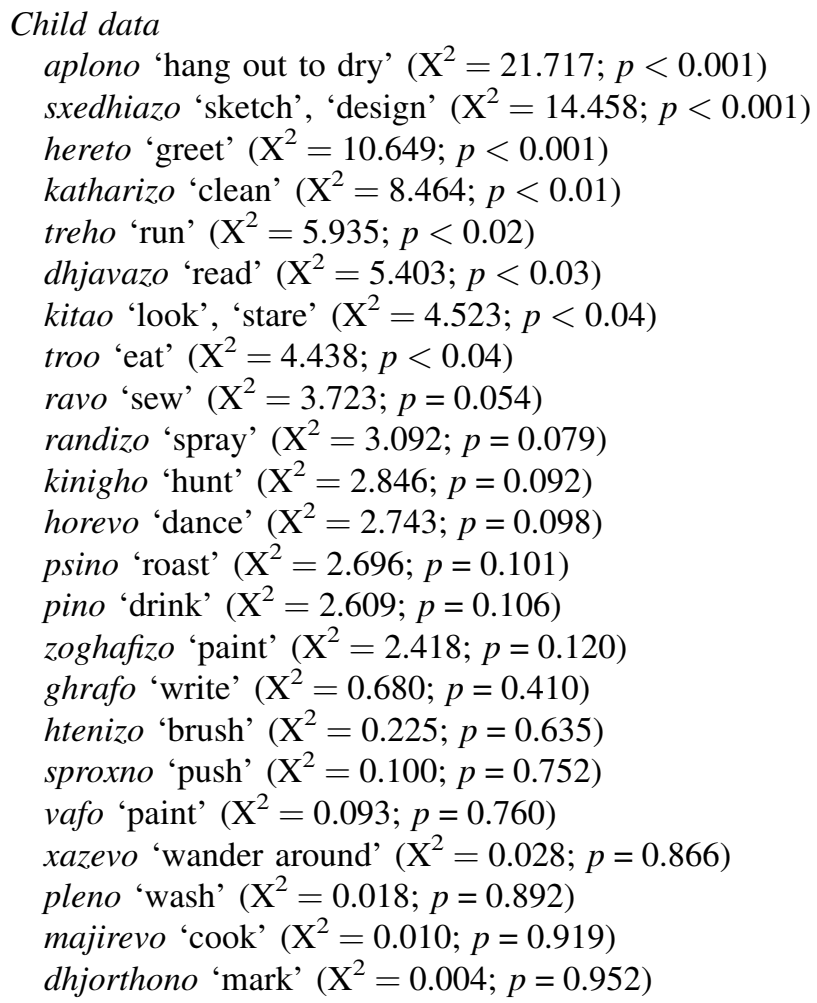

\section{References}

Arad, M., 1998. VP structure and the syntax-lexicon interface. Ph.D. dissertation, UCL.

Babko-Malaya, O., 1999. Zero morphology: a study of aspect, argument structure and case. Ph.D. dissertation, The State University of New Jersey, New Brunswick.

Basilico, D., 1998. Object position and predication forms. Natural Language and Linguistic Theory 16, $541-595$.

Borer, H., 1994. The projection of arguments. In: Benedicto, E., Runner, J. (Eds.), Functional Projections. University of Massachusetts Occasional Papers 17, pp. 19-46.

Borer, H., 1998. Deriving passives without theta-grids. In: Lapointe, S., Brentari, D., Farrell, P. (Eds.), Morphology and its Relation to Phonology and Syntax. CSLI Publications, Stanford, pp. 60-99.

Borer, H., 2004. The grammar machine. In: Alexiadou, A., Anagnostopoulou, E. (Eds.), The Unaccusativity Puzzle. Oxford University Press, Oxford.

Borer, H., 2005. In Name Only. Structuring Sense, vol. I. Oxford University Press, Oxford.

Bowers, J., 2002. Transitivity. Linguistic Inquiry 33, 183-224.

Brody, M., 1995. Logico-Lexical Form: A Radically Minimalist Approach. MIT Press, Cambridge, MA.

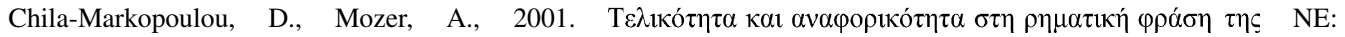

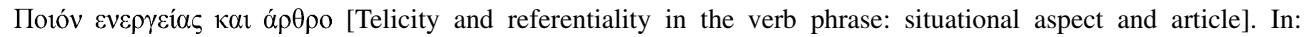
Agouraki, Y., Arvaniti, A., Davy, J., Goutsos, D., Karyolemou, M., Panayiotou-Triantaphyllopoulou, A., Papapavlou, A., Pavlou, A., Roussou, A. (Eds.), Proceedings of the Fourth International Conference on Greek Linguistics, Nicosia, Cyprus. University Studio Press, Thessaloniki, pp. 138-145.

Chomsky, N., 1981. Lectures on Government and Binding. Foris, Dordrecht.

Chomsky, N., 1986. Knowledge of Language: Its Nature, Origin and Use. Praeger, New York.

Chomsky, N., Lasnik, H., 1993. The theory of principles and parameters. In: Jacobs, J., von Stechow, A., Sternefeld, W., Vannemann, Th. (Eds.), Syntax: An International Handbook of Contemporary Research, vol. 1. Walter de Gruyter, Berlin, pp. 506-569. 
Comrie, B., 1976. Aspect. An Introduction to the Study of Verbal Aspect and Related Problems. Cambridge University Press, Cambridge.

Cummins S., Roberge, Y., 2004. Null objects in French and English. In: Auger, J., Clements, J.C., Vance, B. (Eds.), Contemporary Approaches to Romance Linguistics: Selected papers from the 33rd Linguistic Symposium on Romance Languages (LSRL). John Benjamins, Amsterdam, pp. 121-138.

Dahl, O., 1985. Tense and Aspect Systems. Basil Blackwell, New York.

Erteschik-Shir, N., Rapoport, T., 2004. Aspectual focus: bare aspect. In: Gueron, J., Lecarme, J. (Eds.), The Syntax of Time. MIT Press, Cambridge, MA, pp. 217-234.

Farrell, P., 1990. Null objects in Brazilian Portuguese. Natural Language and Linguistic Theory 8, 325-346.

Giannakidou, A., Merchant, J., 1997. On the interpretation of null indefinite objects in Greek. Studies in Greek Linguistics. Proceedings of the 10th Annual Meeting of the Department of Linguistics, Faculty of Philosophy, Aristotle University of Thessaloniki, Kyriakidis, Thessaloniki, pp. 290-303.

Goldberg, A., 2005. Constructions, lexical semantics and the Correspondence Principle: accounting for generalizations and subregularities in the realization of arguments. In: Erteschik-Shir, N., Rapoport, T. (Eds.), The Syntax of Aspect. Oxford University Press, Oxford.

Grimshaw, J., Vikner, S., 1993. Obligatory adjuncts and the structure of events. In: Reuland, E., Abraham, W. (Eds.), Knowledge and Language. Kluwer Academic Publishers, Dordrecht.

Hale, K., Keyser, J., 1986. Some Transitive Alternations in English. MIT Press, Cambridge, MA.

Hale, K., Keyser, J., 1993. On argument structure and the lexical representation of syntactic relations. In: Hale, K., Keyser, K. (Eds.), The View from Building 20. MIT Press, Cambridge, MA, pp. 53-110.

Hale, K., Keyser, J., 2002. Prolegomenon to a Theory of Argument Structure. MIT Press, Cambridge, MA.

Hopper, P.J., Thompson, S.A., 1980. Transitivity in grammar and discourse. Language 56, 251-300.

Hornstein, N., 1990. As Time Goes By: Tense and Universal Grammar. MIT Press, Cambridge, MA.

Horrocks, G., Stavrou, M., 2003. Actions and their results in Greek and English: the complementarity of morphologically encoded (viewpoint) aspect and syntactic resultative predication. Journal of Semantics 20, 297-327.

Horrocks, G., Stavrou, M., in press. Grammaticalised aspect and spatio-temporal culmination. To appear in Lingua.

van Hout, A., 1992. Linking and projection based on event structure. Ms. Tilburg University.

van Hout, A., 1996. Event semantics of verb frame alternations: a case study of Dutch and its acquisition. Ph.D. dissertation, Tilburg University.

van Hout, A., 1997. Learning telicity: acquiring argument structure and the syntax-semantics of direct objects in Dutch. In: Hughes, E., Hughes, M., Greenhill, A. (Eds.), BUCLD 21: Proceedings of the 21st Annual Boston University Conference on Language Development. Cascadilla Press, Somerville, MA, pp. 678-688.

Huang, C.-T.J., 1984. On the distribution and reference of empty pronouns. Linguistic Inquiry 15, 531-574.

Jackendoff, R., 1986. Semantics and Cognition. MIT Press, Cambridge, MA.

Joseph, B., 1983. The synchrony and diachrony of the Balkan infinitive. A study in areal, general and historical linguistics. Cambridge University Press, Cambridge.

Kowaluk, A., 2001. The acquisition of determiners and pronouns in English L2. Ph.D. dissertation, Cambridge, UK.

Kuroda, S.-Y., 1972. The categorical judgment and the thetic judgment. Foundations of Language 9, $153-185$.

Ladusaw, W., 1994. Thetic and categorical, stage and individual, weak and strong. In: Harvey, M., Santelman, L. (Eds.), Proceedings from Semantics and Linguistic Theory IV. Cornell University Department of Modern Languages and Linguistics, Ithaca, NY, pp. 220-229.

Milsark, G., 1974. Existential sentences in English. Ph.D. dissertation. MIT, Cambridge, MA.

Mirambel, A., 1959. La Langue Grecque Moderne [The Modern Greek Language]. Klincksieck, Paris.

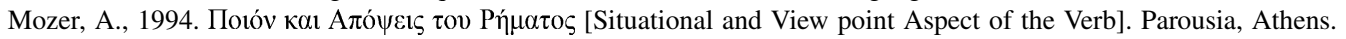
Panagiotidis, Ph., 2003. Empty nouns. Natural Language and Linguistic Theory 21, 381-432.

Pirvulescu, M., Roberge, Y., 1999. Romanian, objects and imperative constructions. In: Authier, J.-M., Bullock, B.E., Reed, L.A. (Eds.), Formal Perspectives on Romance Linguistics. John Benjamins, Amsterdam.

Raposo, E., 1986. On the null object in European Portuguese. In: Jaeggli, O., Silva-Corvalán, C. (Eds.), Studies in Romance Linguistics 24. Foris, Dordrecht, pp. 373-390.

Rappaport-Hovav, M., Levin, B., 1998. Building verb meanings. In: Butt, M., Geuder, W. (Eds.), The Projection of Arguments: Lexical and Compositional Factors. CSLI Publications, Stanford, CA, pp. 97-134.

Rappaport-Hovav, M., Levin, B., 2001. An event structure account of English resultatives. Language 77, $766-797$.

Ritter, E., Rosen, S., 1998. Delimiting events in syntax. In: Butt, M., Geuder, W. (Eds.), The Projection of Arguments: Lexical and Compositional Factors. CSLI Publications, Stanford, CA, pp. 135-164.

Rizzi, L., 1982. Issues in Italian Syntax. Foris, Dordrecht.

Rizzi, L., 1986. Null objects in Italian and the theory of pro. Linguistic Inquiry 17, 501-557. 
Roberge, Y., 2002. Transitivity requirement effects and the EPP. Paper presented at the Western Conference on Linguistics (WECOL), November 2002, Vancouver.

Roussou, A., Tsimpli, I.M., 2006. On VSO again! Journal of Linguistics 42, 317-354.

Sanz, M., 2000. Events and Predication: A New Approach to Syntactic Processing in English and Spanish. John Benjamins, Amsterdam.

Schulz, P., Wittek, A., 2003. Opening doors and sweeping floors: what children with specific language impairment know about Telic and Atelic verbs. In: Beechley, B., Brown, A., Conlin, F. (Eds.), BUCLD 27: Proceedings of the 23rd annual Boston University Conference on Language Development. Cascadilla Press, Somerville, MA, pp. 727-738.

Schulz, P., Wymann, K., Penner, Z., 2001. The early acquisition of verb meaning in German by normally developing and language impaired children. Brain and Language 77, 407-418.

Smith, C.S., 1991. The Parameter of Aspect. Kluwer Academic Publishers, Dordrecht.

Smith, N., 1990. Observations on the pragmatics of tense. UCL Working Papers in Linguistics 2, 82-94.

Sioupi, A., 2002. On the syntax and semantics of verb-complement constructions that involve 'creation': a comparative study in Greek and German. In: Abraham, W., Zwart, J.-W. (Eds.), Issues in Formal German(ic) Typology. John Benjamins, Amsterdam, pp. 263-284.

Tenny, C., 1987. Grammaticalizing aspect and affectedness. Ph.D. Dissertation, MIT, Cambridge, MA.

Thrift, E., Hyams, N., 2001. The role of aspect in licensing object drop in child Dutch. In: Do, A.H.-J., Domínguez, L., Johansen, A. (Eds.), BUCLD 25: Proceedings of the 21st annual Boston University Conference on Language Development. Cascadilla Press, Somerville, MA, pp. 756-767.

Travis, L., 2000. Event structure in syntax. In: Tenny, C., Pustejovski, J. (Eds.), Events as Grammatical Objects: The Converging Perspectives of Lexical Semantics and Syntax. CSLI Publications, Stanford, CA, pp. 145-185.

Traxler, M.J., 2002. Plausibility and subcategorization preference in children's processing of temporarily ambiguous sentences: evidence form self-paced reading. Quarterly Journal of Experimental Psychology (A) 55, 75-96.

Tsangalidis, A., 1999. "Will" and "tha": A Comparative Study of the Category Future. University Studio Press, Thessaloniki.

Tsimpli, I.M., 1999. Null operators, clitics and identification: a comparison between Greek and English. In: Alexiadou, A., Horrocks, G., Stavrou, M. (Eds.), Studies in Greek Syntax. Kluwer, Dordrecht, pp. 241-262.

Verkuyl, H.J., 1993. A theory of aspectuality: the interaction between temporal and atemporal structure. In: Cambridge Studies in Linguistics 64. Cambridge University Press, Cambridge.

Wright, S., Levin, B., 2000. Unspecified object contexts with activity and change of state verbs. Paper presented at the 74th LSA Annual Meeting, Chicago, IL. 